TITLE:

\title{
BMPR2 gene mutation in pulmonary arteriovenous malformation and pulmonary hypertension: a case report.
}

\section{AUTHOR(S):}

Handa, Tomohiro; Okano, Yoshiaki; Nakanishi, Norifumi; Morisaki, Takayuki; Morisaki, Hiroko; Mishima, Michiaki

\section{CITATION:}

Handa, Tomohiro ...[et al]. BMPR2 gene mutation in pulmonary arteriovenous malformation and pulmonary hypertension: a case report.. Respiratory investigation 2014, 52(3): 195-198

\section{ISSUE DATE:}

2014-05

URL:

http://hdl.handle.net/2433/188945

\section{RIGHT:}

(C) 2013 The Japanese Respiratory Society. Published by Elsevier Japan KK; This is not the published version. Please cite only the published version.; この論文は出版社版でありません。引用の際には出版社版を ご確認ご利用ください。 


\section{$B M P R 2$ gene mutation in pulmonary arteriovenous malformation and pulmonary} hypertension: a case report

\section{Author names and affiliations:}

Tomohiro Handa, MD, PhD ${ }^{\mathrm{a}}$ (hanta@ kuhp.kyoto-u.ac.jp), Yoshiaki Okano, MD, PhD ${ }^{\mathrm{b}}$ (yokano2@kuhp.kyoto-u.ac.jp), Norifumi Nakanishi, $\mathrm{MD}, \mathrm{PhD}^{\mathrm{c}}$

(nnakanis@hsp.ncvc.go.jp), Takayuki Morisaki, MD, PhD ${ }^{\mathrm{d}}$ (morisaki@ri.ncvc.go.jp),

Hiroko Morisaki, MD, $\mathrm{PhD}^{\mathrm{d}}$ (hirokom@ri.ncvc.go.jp), Michiaki Mishima, MD, $\mathrm{PhD}^{\mathrm{a}}$ (mishima@kuhp.kyoto-u.ac.jp)

a Department of Respiratory Medicine, Graduate School of Medicine, Kyoto University,

Kyoto, Japan

${ }^{\mathrm{b}}$ Department of Internal Medicine, Hanwa Daini Senboku Hospital, Sakai, Japan

${ }^{c}$ Division of Pulmonary Circulation, Department of Cardiovascular Medicine, National

Cerebral and Cardiovascular Center, Suita, Japan

${ }^{\mathrm{d}}$ Department of Bioscience and Genetics, National Cerebral and Cardiovascular Center 
Research Institute, Suita, Japan

Short title: Pulmonary hypertension in PAVM

Correspondence to: Tomohiro Handa MD, PhD

Assistant Professor, Department of Rehabilitation Medicine/Respiratory Medicine,

Kyoto University Hospital, 54 Shogoin Kawahara-cho, Sakyo, Kyoto 606-8507, Japan

Telephone number: +81 75751 3830; Fax number: +81 757514643

E-mail address: hanta@kuhp.kyoto-u.ac.jp 


\section{Abstract}

The transforming growth factor- $\beta$ superfamily signaling pathway is thought to be involved in the pathogenesis of pulmonary arteriovenous malformation (PAVM). However, the association between bone morphogenetic protein receptor type 2 (BMPR2) gene mutations and PAVM remains unclear. We present a case of concurrent PAVM and pulmonary arterial hypertension $(\mathrm{PAH})$, with a deletion mutation in exon 6 and exon 7 of the BMPR2 gene. Drug treatment for PAH improved the patient's hemodynamics and exercise capacity, but worsened oxygenation. This case suggests that $B M P R 2$ gene mutation may be associated with the complex presentation of PAVM combined with PAH.

Keywords: ambrisentan, bone morphogenetic protein receptor type 2, pulmonary arterial hypertension, pulmonary arteriovenous malformation, sildenafil 


\section{Abbreviation list}

ACVRL1 = activin A receptor type 2-like 1

$\mathrm{BMP}=$ bone morphogenetic protein

$B M P R 2=$ bone morphogenetic protein receptor type 2

$\mathrm{CI}=$ cardiac index

$\mathrm{CO}=$ cardiac output

MADH4 = decapentaplegic homologue 4

$\mathrm{ENG}=$ endoglin

HHT = hereditary hemorrhagic telangiectasia

HRCT $=$ high resolution computed tomography

MADH4 = decapentaplegic homologue 4

$\mathrm{PAH}=$ pulmonary arterial hypertension

$\mathrm{PAP}=$ pulmonary artery pressure

PAVM = pulmonary arteriovenous malformation

PCWP = pulmonary capillary wedge pressure

$\mathrm{PVR}=$ pulmonary vascular resistance 
RHC $=$ right heart catheterization

TGF- $\beta=$ transforming growth factor- $\beta$ 


\section{Introduction}

Hereditary pulmonary arterial hypertension $(\mathrm{PAH})$ and hereditary hemorrhagic

telangiectasia (HHT) are associated with mutations in the transforming growth factor- $\beta$

(TGF- $\beta$ ) and bone morphogenetic protein (BMP) pathways and have a major impact on

lung vasculature $[1,2]$. Pulmonary arteriovenous malformation (PAVM) is a

complication of HHT, occurring in $20-40 \%$ of patients. Conversely, approximately

80-95\% of PAVM cases are associated with HHT [3]. The most frequent cause of

hereditary PAH is bone morphogenetic protein receptor type 2 (BMPR2) gene mutation.

However, its association with HHT or PAVM remains unclear. We present a case of

concurrent PAVM and PAH, with a novel deletion mutation in exon 6 and exon 7 of the

$B M P R 2$ gene.

\section{Case report}

A 33-year-old woman was referred to a clinic due to cough, where she was found to have a chest CT abnormality. At presentation in our hospital, she had no chest

symptoms. Physical examination revealed a body temperature of $36.5^{\circ} \mathrm{C}$, blood pressure 
of $116 / 78 \mathrm{mmHg}$, and pulse rate of 80 beats/min with a regular rhythm. Heart and lung auscultation revealed no abnormalities, and there was no pretibial edema. There was no sign of mucocutaneous telangiectases on the fingers, lips, or oral cavity. Additionally, there was no previous history of drug abuse. Moreover, there was no family history of HHT, recurrent nasal hemorrhage, or abnormal chest shadow. Laboratory tests showed mild polycythemia, and autoantibody screening for collagen vascular diseases was negative. Electrocardiography and arterial blood gas at rest revealed no abnormalities. Pulmonary function tests showed decreased diffusing capacity (supplementary Table S1). Chest HRCT revealed meandering vasculature in bilateral lung fields (Fig. 1A). A 3-dimensional reconstruction image showed a saccular aneurysm with an afferent artery and efferent vein, suggesting the presence of PAVM (Fig. 1B). Tc MAA scintigraphy and the $100 \%$ oxygen inhalation method showed a mild increase in the arteriovenous shunt ratio ( $8.4 \%$ and $5.1 \%$, respectively), and contrast echocardiography revealed microbubble flow from the pulmonary vein to the left atrium, such that LA enhancement was delayed from RA enhancement by more than 3 cardiac cycles. Based on these findings, the patient was diagnosed with multiple PAVMs. Abdominal CT and 
brain MRI showed no AVM in other organs, and portal hypertension was ruled out by abdominal echocardiogram. According to the International Clinical Diagnostic Criteria for HHT, a diagnosis of HHT was unlikely [4].

Right heart catheterization (RHC) revealed concurrent pulmonary arterial hypertension as follows: pulmonary artery pressure (PAP) 55/29 (41) $\mathrm{mmHg}$, pulmonary capillary wedge pressure (PCWP) $14 \mathrm{mmHg}$, cardiac output (CO) 3.81 $\mathrm{L} / \mathrm{min}$, cardiac index $(\mathrm{CI}) 2.75 \mathrm{~L} / \mathrm{min} / \mathrm{m}^{2}$, pulmonary vascular resistance (PVR) 7.1 Wood. A series of examinations showed no evidence of left-sided heart failure, pulmonary embolism, obstructive or restrictive pulmonary disease, portal hypertension, or connective tissue disease. Mutation analysis of entire coding exons and adjacent introns of the BMPR2, endoglin (ENG), activin A receptor type 2-like 1 (ACVRL1), and decapentaplegic homologue $4(M A D H 4)$ genes was performed by bidirectional direct DNA sequencing after PCR amplification of genomic DNA. Analysis of large-scale gene rearrangements in $B M P R 2, E N G$, and $A C V R L 1$ was performed using multiplex ligation-dependent probe amplification. This genetic study was approved by the ethics committees of the National Cerebral and Cardiovascular Center Research Institute 
(approval number M20-01-3, November 17, 2011). No ACVRL1 or ENG mutation was identified. However, a heterogeneous germline deletion mutation of exon 6 and exon 7 of the $B M P R 2$ gene was identified, which was further confirmed by real-time quantitative PCR using TaqMan probes.

Because the patient was asymptomatic, she was followed-up without any specific treatment. The patient experienced mild dyspnea after she delivered a child 16 months after the diagnosis of PAVM and PAH. Follow up RHC showed worsening of PH (PAP 81/41 (56) mmHg, PCWP 14 mmHg, CO 3.59 L/min, CI 2.60 L/min/m², PVR 10.9 Wood), although the shunt ratio was unchanged (Fig. 2). PAH-specific treatment with sildenafil (60 mg/day) and ambrisentan (5-10 mg/day) improved hemodynamics, exercise capacity, and symptoms, although oxygenation at rest and during exercise deteriorated, accompanied by mild elevation of the shunt ratio (Fig. 2). At present, the combination drug treatment is being continued with careful follow-up of the patient's oxygenation.

\section{Discussion}


We presented a case of PAVM combined with PAH, with a BMPR2 gene mutation. The diagnosis of PAVM was made based on compatible findings of chest HRCT and contrast echocardiography along with an increased shunt ratio. There was no other comorbidity likely to cause PAVM, suggesting that PAVM was associated with the BMPR2 gene mutation. Aside from PAVM, this patient had no features suggestive of HHT. However, because of the relatively young age of the patient, it is possible that HHT will develop in the future. Because the clinical phenotype of HHT becomes easier to identify with age, the age of onset in a Japanese cohort was reported to be $>30$ years in $27 \%$ of patients and $>40$ years in $8 \%$ of patients [5].

Although PAH and HHT have different characteristics with regard to endothelial cell and smooth muscle cell proliferation, they may share common genetic backgrounds $[1,2,6]$. Mutations in the $B M P R 2$ gene have been associated with $80 \%$ of familial PAH and $15-40 \%$ of idiopathic PAH cases, whereas about $80 \%$ of HHT cases are associated with heterozygous germline mutations of ENG, ACVRL1, and MADH4 [1, 3]. Approximately 30 families with both PAH and HHT have been described, and most of them carried ACVRL1 gene mutations [2, 6, 7, 8]. To date, there has been only one 
case report of a patient with a BMPR2 mutation who had concurrent PAH and HHT with

PAVM [9]. The present case, along with the previous case, suggests that BMPR2 gene

mutation may be associated with the complex presentation of PAVM combined with

PAH. Additionally, pre-existing PAH may have caused the PAVM. In previous reports of concurrent PAH and PAVM, the authors speculated that PAH may have caused PAVM by rupture of the hypoplastic vascular septa, an increase in the size of a previously developed arteriovenous fistula, or an enlargement of anatomically normal arteriovenous shunts $[10,11]$. Unfortunately, genetic abnormalities were not investigated in these reports.

It remains unknown why gene mutations of common pathways cause different phenotypes, and why the two phenotypes co-exist in a subset of cases. It is speculated that differential distribution of the receptors and alternative ligand-receptor responses may play a role $[1,12]$. BMP9 acts through ACVRL1 and SMAD1, 5, 8, and the signal is balanced by BMPR2 and ActR2A [12]. BMPR2 gene mutation does not usually lead to overt HHT, because ActR2A compensates. It is speculated that in patients with HHT and BMPR2 gene mutation, this compensation may be incomplete [9]. In our patient, 
the entire genomic deletion of exon 6 and exon 7 of the BMPR2 gene, containing $231 \mathrm{bp}$ and $115 \mathrm{bp}$ of the coding sequence, respectively, would result in a frame shift transcript lacking 346 bp of the coding sequence, including the region coding for the kinase domain. The mutated transcript is expected to be degraded by nonsense-mediated mRNA decay, which supposedly leads to haploinsufficiency of the $B M P R 2$ gene product. This mutation has not been reported in the literature so far, and differs from that reported previously in concurrent HHT and PAH (nonsense mutation in exon 10) [9]. Further investigation is necessary to elucidate mechanisms by which these mutations cause both PAVM and PAH.

In the present case, PAH worsened after the delivery of a child. After the diagnosis of PAVM and PAH, we instructed the patient regarding the risks of becoming pregnant, such as an enlargement of the PAVM and increased risk of pulmonary hemorrhage and cerebrovascular events $[13,14]$. Additionally, PAH during pregnancy is associated with a high risk to the parturient [15]. Because of the risk posed by PAVM and PAH, we believe that pregnancy should be avoided in this situation.

The patient had no hypoxemia during rest, whereas oxygen desaturation was 
observed on exercise. This may be due to a small increase in the shunt ratio at rest, and the shunt ratio and ventilation/perfusion mismatch may have increased during exercise because of the increased vascular resistance of the pulmonary arteries. Regarding the medical treatment of patients with PAVM and PAH, some authors do not recommend vasodilator therapy because of a potential increase of arteriovenous shunt volume, while others have demonstrated the effectiveness and safety of endothelin receptor antagonists in this disease $[16,17]$. In our case, combination therapy improved exercise capacity and hemodynamics, though oxygenation deteriorated, with a mild increase of the shunt ratio. One possible explanation is that the increased shunt ratio caused by the vasodilator worsened hypoxemia, whereas the drug decreased pulmonary vascular resistance, leading to increased cardiac output and improved exercise capacity. Taking the potential adverse effect on shunt ratio into account, careful follow-up of oxygenation is required when PAH-specific therapy is applied to patients with PAVM and PAH.

In conclusion, PAVM and PAH can occur in association with germline BMPR2 gene mutations. Screening for BMPR2 gene mutation should be considered in this 
complex disease.

\section{Acknowledgement}

We would like to acknowledge the patient, her family, and the nurses involved in her

care. We thank Dr. Yoshinobu Konishi, Dr. Kohei Ikezoe, Dr. Kiminobu Tanizawa, Dr.

Kensaku Aihara (Department of Respiratory Medicine, Graduate School of Medicine,

Kyoto University), Dr. Reiko Hozo (Department of Cardiovascular medicine, Graduate

School of Medicine, Kyoto University), Dr. Sonoko Nagai (Kyoto Central

Clinic/Clinical Research Center), and Prof. Kazuo Chin (Department of Respiratory

Care and Sleep Control Medicine, Graduate School of Medicine, Kyoto University) for their contribution to the clinical assessment. We also thank Dr. Takeshi Kubo

(Department of Diagnostic Imaging and Nuclear Medicine Graduate School of

Medicine, Kyoto University) for his contribution in the radiological assessment.

\section{Funding Sources}

This study was supported by the Respiratory Failure study group and Diffuse Lung Disease study group from the Ministry of Health, Labour and Welfare, Japan (H23-Nanchi-Ippan-023 and 024). 


\section{Conflict of interest}

The authors have no conflicts of interest. 


\section{References}

[1] Upton PD, Morrell NW. TGF-beta and BMPR-II pharmacology--implications for pulmonary vascular diseases. Curr Opin Pharmacol 2009;9:274-80.

[2] Trembath RC, Thomson JR, Machado RD, et al. Clinical and molecular genetic features of pulmonary hypertension in patients with hereditary hemorrhagic telangiectasia. N Engl J Med 2001;345:325-34.

[3] Wong HH, Chan RP, Klatt R, et al. Idiopathic pulmonary arteriovenous malformations: clinical and imaging characteristics. Eur Respir J 2011;38:368-75.

[4] Shovlin CL, Guttmacher AE, Buscarini E, et al. Diagnostic criteria for hereditary hemorrhagic telangiectasia (Rendu-Osler-Weber syndrome). Am J Med Genet 2000;91:66-7.

[5] Shioya T, Kanazawa T. Osler disease: Hereditary Hemorrhagic Telangiectasia.

Kokyu 1989;8:707-12. [in Japanese]

[6] Harrison RE, Flanagan JA, Sankelo M, et al. Molecular and functional analysis identifies ALK-1 as the predominant cause of pulmonary hypertension related to hereditary haemorrhagic telangiectasia. J Med Genet 2003;40:865-71. 
[7] Abdalla SA, Gallione CJ, Barst RJ, et al. Primary pulmonary hypertension in families with hereditary haemorrhagic telangiectasia. Eur Respir J 2004;23:373-7.

[8] Smoot LB, Obler D, McElhinney DB, et al. Clinical features of pulmonary arterial hypertension in young people with an ALK1 mutation and hereditary haemorrhagic telangiectasia. Arch Dis Child 2009;94:506-11.

[9] Rigelsky CM, Jennings C, Lehtonen R, et al. BMPR2 mutation in a patient with pulmonary arterial hypertension and suspected hereditary hemorrhagic telangiectasia. Am J Med Genet A 2008;146A:2551-6.

[10] Yoshida F, Terasawa A, Hosoe M, et al. Long-term observation of a case of pulmonary arteriovenous fistula with pulmonary hypertension. Intern Med 1995;34:574-6.

[11] Sperling DC, Cheitlin M, Sullivan RW, et al. Pulmonary arteriovenous fistulas with pulmonary hypertension. Chest 1977;71:753-7.

[12] Upton PD, Davies RJ, Trembath RC, et al. Bone morphogenetic protein (BMP) and activin type II receptors balance BMP9 signals mediated by activin receptor-like kinase-1 in human pulmonary artery endothelial cells. J Biol Chem 
2009;284:15794-804.

[13] Shovlin CL, Winstock AR, Peters AM, et al. Medical complications of pregnancy in hereditary haemorrhagic telangiectasia. QJM 1995;88:879-87.

[14] Esplin MS, Varner MW. Progression of pulmonary arteriovenous malformation during pregnancy: case report and review of the literature. Obstet Gynecol

Surv 1997;52:248-53.

[15] Safdar Z. Pulmonary arterial hypertension in pregnant women. Ther Adv Respir

Dis 2013;7:51-63.

[16] Bonderman D, Nowotny R, Skoro-Sajer N, et al. Bosentan therapy for pulmonary arterial hypertension associated with hereditary haemorrhagic telangiectasia. Eur J Clin Invest 2006;36:71-2.

[17] Chang SA, Jang SY, Ki CS, et al. Successful bosentan therapy for pulmonary arterial hypertension associated with hereditary hemorrhagic telangiectasia. Heart Vessels 2011;26:231-4. 


\section{Figure legends}

Figure 1. A. Chest HRCT on admission. Multiple meandering feeding vessels (arrows)

are found in bilateral lung fields. B. 3-dimentional reconstruction image of chest CT. A saccular aneurysm $(5.8 \mathrm{~mm}$ in diameter, arrowhead) with an afferent artery $(2.6 \mathrm{~mm}$ in diameter) and efferent vein (2.7 $\mathrm{mm}$ in diameter) is shown (arrows). PA, pulmonary artery; PV, pulmonary vein; AA, afferent artery; EV, efferent vein.

Figure 2. Clinical course of the patient. PH deteriorated after the delivery of a child.

After 5 months of combination treatment for $\mathrm{PH}$, hemodynamics and clinical symptoms improved. *Period from the start of PAH treatment. NYHA-FC, New York Heart Association Functional Class; sPAP, systolic pulmonary artery pressure estimated by Doppler echocardiogram; PAP, pulmonary artery pressure measured by right heart catheter; CI, cardiac index; PVR, pulmonary venous resistance; BNP, B-type natriuretic peptide; 6MWD, six-minute walk distance; $\mathrm{Min}_{\mathrm{SpO}}$, Minimal oxygen saturation during six-minute walk test. 


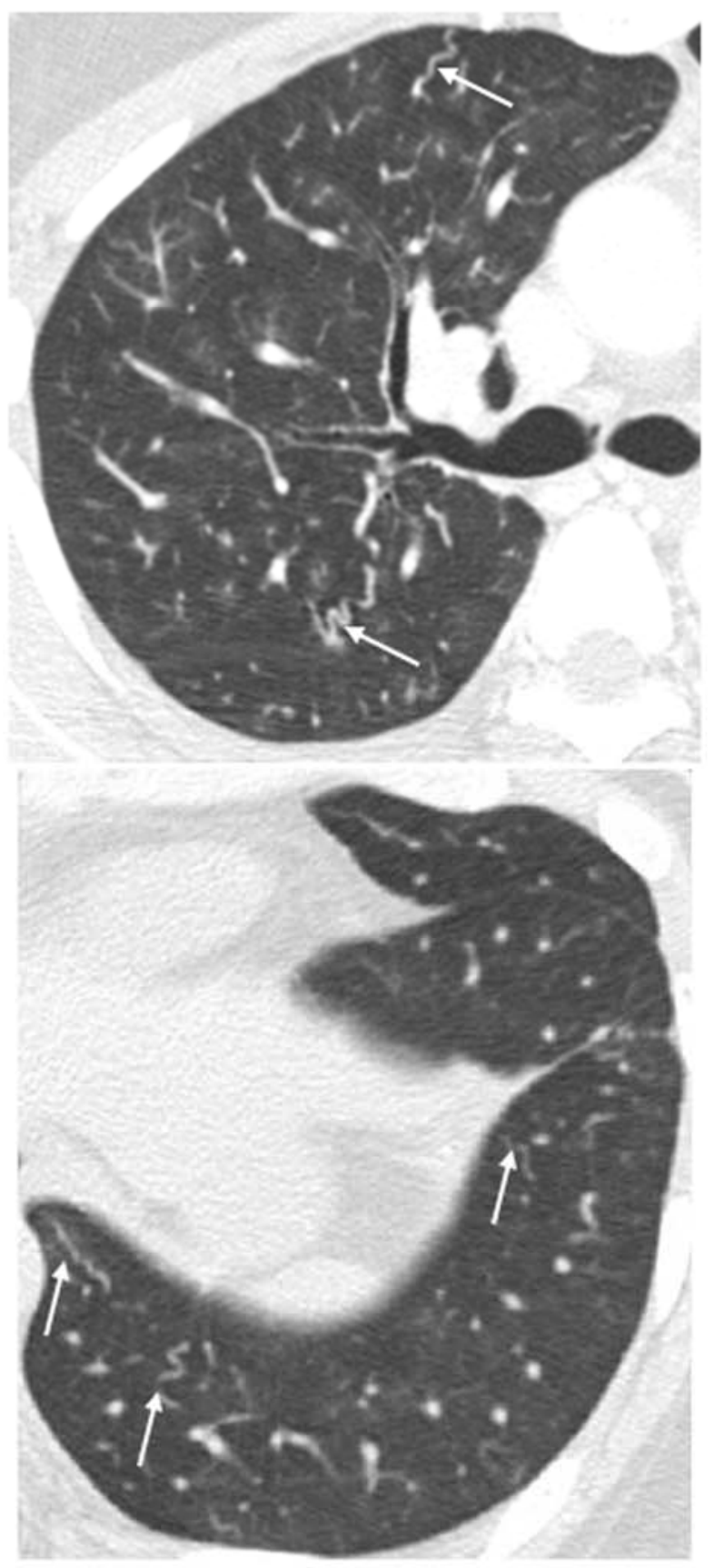

A
Figure 1



B 
Figure 2

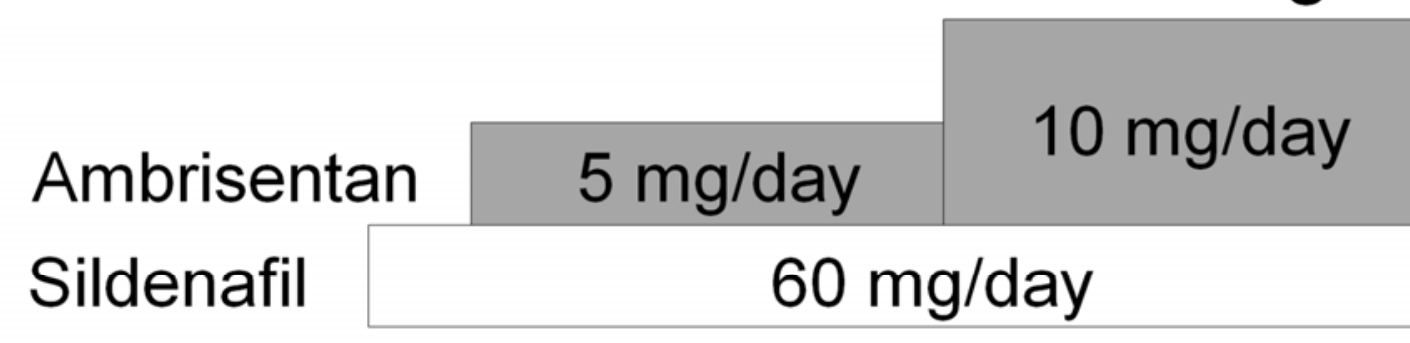

At diagnosis Before treatment 7 days* 40 days* 5 months*

\begin{tabular}{|c|c|c|c|c|c|}
\hline NYHA-FC & I & II & I & I & I \\
\hline sPAP $(\mathrm{mmHg})$ & 42 & 87 & 81 & 57 & 45 \\
\hline $\mathrm{PAP}(\mathrm{mmHg})$ & $55 / 29(41)$ & $81 / 41(56)$ & - & - & $50 / 19(34)$ \\
\hline $\mathrm{Cl}\left(\mathrm{L} / \mathrm{min} / \mathrm{m}^{2}\right)$ & 2.75 & 2.60 & - & - & 2.88 \\
\hline PVR (Wood) & 7.1 & 10.9 & - & - & 6.5 \\
\hline BNP (pg/mL) & 7.4 & 7.5 & 21.5 & 17.1 & 7.4 \\
\hline Shunt ratio (\%) & 8.1 & 7.8 & 11.4 & 8.3 & 9.5 \\
\hline 6MWD (m) & 347 & 390 & 427 & 461 & 466 \\
\hline $\operatorname{Min} \mathrm{SpO}_{2}(\%)$ & 97 & 95 & 87 & 80 & 83 \\
\hline $\mathrm{A}-\mathrm{aDO}_{2}$ (torr) & 17.9 & 12.4 & 17.5 & 16.8 & 28.1 \\
\hline
\end{tabular}


Table S1. Laboratory test results on admission

\section{$\langle\mathrm{CBC}>$}

White blood cells

Red blood cells

Hemoglobin

Platelets

$<$ Coagulation $>$

PT (sec)

PT (act)

APTT

Fib

D-dimer

$<$ Serology $>$

CRP

Anti-nuclear antibody

Anti-CCP antibody

Anti-centromere antibody

Anti-Scl-70 antibody

Anti-RNP antibody

$<$ Biochemistry $>$

LDH (129-241)

CPK (35-141)
TP (6.3-8.1)

$7.2 \mathrm{~g} / \mathrm{dL}$

$4.6 \times 10^{9} / \mathrm{L} \quad \gamma$-globulin $(10.6-20.5)$

$15.2 \%$

$4.78 \times 10^{12} / \mathrm{L} \quad<$ Arterial blood gas (room air)>

$15.2 \mathrm{~g} / \mathrm{dL} \quad \mathrm{pH}$

7.401

$207 \times 10^{9} / \mathrm{L} \quad \mathrm{PaO}_{2}$

$81.9 \mathrm{mmHg}$

$\mathrm{PaCO}_{2}$

$40.2 \mathrm{mmHg}$

$11.6 \mathrm{~s} \quad \mathrm{HCO}_{3}^{-}$

$24.4 \mathrm{mmol} / \mathrm{L}$

$100 \% \quad \mathrm{BE}$

$0.2 \mathrm{mEq} / \mathrm{L}$

$27.2 \mathrm{~s} \quad<$ Pulmonary function tests>

$245 \mathrm{mg} / \mathrm{dL} \quad \% \mathrm{VC}$

$80.1 \%$

$0.2 \mathrm{pg} / \mathrm{mL} \quad \% \mathrm{FEV} 1$

$75.5 \%$

FEV1/FVC

$87.9 \%$

$0.0 \mathrm{mg} / \mathrm{dL} \quad \%$ DLCO

$56.9 \%$

$<\times 40 \quad \%$ DLCO /VA

$80.5 \%$

negative

negative

negative

184 IU/L

$69 \mathrm{IU} / \mathrm{L}$ 
abbreviations: APTT, activated partial thromboplastin time; $\mathrm{CCP}$, cyclic citrullinated peptide; RNP, ribonucleoprotein; $\mathrm{LDH}$, lactate dehydrogenase; $\mathrm{CPK}$, creatine phosphokinase; PT, prothrombin time; TP, total protein; VC, vital capacity; FEV, forced expiratory volume; FVC, forced vital capacity; DLCO, diffusing capacity for carbon monoxide. 